\title{
Improving Bioavailability of Gallic Acid and Quercetin by Designing Polymeric Nanoparticle Formulation
}

poournima shamrao Patil ( $\sim$ poournima6@gmail.com )

Ashokrao Mane College of Pharmacy

Suresh Ganapati killedar

shree Sant Gajana Maharaj college of pharmacy Mahagaon

\section{Research Article}

Keywords: Gallic acid, Quercetin, Polyherbal nanoparticles, Polyherbal extract, colorectal cancer

Posted Date: December 28th, 2021

DOI: https://doi.org/10.21203/rs.3.rs-1163868/v1

License: (c) (1) This work is licensed under a Creative Commons Attribution 4.0 International License.

Read Full License 


\section{Abstract \\ Objective}

The pharmacokinetic properties of encapsulated polyherbal nanoparticles (Gallic acid and quercetin nanoparticle) and polyherbal extract (Amla and pomegranate fruit peels) in normal and DMH-induced colorectal cancer in rats was examined in this work.

\section{Method}

Polyherbal nanoparticles such as Gallic acid isolated from amla fruit and quercetin from pomegranate peel extract formulated into polymeric nanoparticle by using probe sonicator and high pressure homogenization.

\section{Result}

In normal and DMH-induced rats, a pharmacokinetic study demonstrated that polyherbal nanoparticles had a typical sustained release profile with a 2-fold increase in bioavailability when compared to polyherbal extract. Based on serum-concentration profiles of polyherbal nanoparticles and polyherbal extract following oral administration, the pharmacokinetic parameters for polyherbal nanoparticles and polyherbal extract were established using a single compartmental approach.

\section{Conclusion}

This research suggests that encapsulating gallic acid and quercetin in polymeric nanoparticles improves oral bioavailability than polyherbal extract of amla and pomegranate peel. Polymeric nanoparticles could be a novel therapeutic possibility for carcinogenesis prevention.

\section{Introduction}

Colorectal cancer (CRC) can be treated with a variety of methods, including curative resection, radiofrequency ablation, radioembolization, and systemic targeted chemotherapy. [1] Chemotherapy helps to the patients survive despite severe side effects such as diarrhea, hand-foot skin disease, tiredness, anorexia, and baldness. Furthermore, multidrug resistance to chemotherapy has emerged as a barrier to CRC treatment. [2, 3] These substantial side effects have prompted researchers to look for innovative colon-targeted drug delivery systems. Nature is a treasure trove of unique and complex chemicals with a wide range of biological effects. Curcumin, Sennosides, Bowsellic acid, taxol, Triphala, quercetin, ginger extract, rhubarb, gallic acid, and other phytoconstituents have a therapeutic effect on a variety of colonic illnesses. Rather than using the whole extract of both fruits, we focused on natural biomolecules such as gallic acid (phenolic) isolated from amla fruit (emblica officinalis) and quercetin 
(flavonoid) isolated from pomegranate fruit (punica granatum) peels to assess the therapeutic role of these active constituents. The purpose of targeted drug delivery is to deliver medications to the colon via the gastrointestinal tract; this necessitates drug protection from the stomach and small intestine release. It can be accomplished by using a drug delivery system that can protect the medication during its passage through the colon, and the drug must be released from the drug delivery system of the colon. Physiological factors such as GI motility, pH of the GIT metabolism, presence of food, and drug stability all affect medication oral bioavailability. [4] Drug pKa, lipid solubility and partition co-efficient, drug solubility, particle size, and drug carrier are all formulation parameters. Drug release is determined by the $\mathrm{pH}$ of the GIT, which ranges from 1.5 to 2.0 in the stomach, 3.0-5.0 in the fasting state, 5.0-6.5 in the small intestine, and 6.4-7.6 in the large intestine. The vast majority of medications are weak acids or bases. [5] As a result, they get ionized to some extent, which is determined by the $\mathrm{pKa}$ or $\mathrm{pH}$ of the biological fluid in which they are dissolved. [6] The biggest worry once the dosage form enters the stomach is how long it will stay there before being emptied into the duodenum. A mechanism like this might discharge the medicine at a distance from the colon. The release of drugs is reliant on enzymes derived from the microflora in the colon. These enzymes are employed to dissolve bonds between an inert carrier and an active agent, allowing the medicine to be released from the formulation.[7]

$\mathrm{PH}$-sensitive polymer-coated, time-dependent, pressure-dependent drug delivery, microbially triggered, and polysaccharide-based approaches are all options for colon-focused drug administration. [8] The timedependent method is based on the notion of delaying medication release until it reaches the colon. During transit through the upper GIT, they offer an initial lag phase of low or no release. In this study, the polymer chitosan was ionically cross linked with multivalent anions such as sodium tripolyphosphate. lonic gelation, the method that produces nanoparticles with diameters of less than $200 \mathrm{~nm}$ and has been shown to encapsulate a variety of biological and active chemicals, has some advantages. Chitosan becomes insoluble $(\mathrm{pH}>6.5)$ as the primary amines get more deprotonated. The adsorption of mucin was affected by the $\mathrm{H}$-bonding and interactions between the phenolic moieties of biomolecules encapsulated into nanoparticles. Poloxamer 407 is a nontoxic hydrophilic copolymer that is commonly utilized as a pharmaceutical excipient due to its ability to stabilize medicines and increase their solubility.[9]

The GMO/chitosan-TPP system is a surface-modified nanoparticulate system that contains GMO as a lipid component and chitosan as a coating polymer to target the colonic area, as well as poloxamer 407 as a stabilizer. The goal of this study was to create gallic acid and quercetin-loaded chitosan nanoparticles (polymeric nanoparticles) using gallic acid extracted from amla fruit and quercetin extracted from pomegranate fruit peels as a model hydrophobic drug, followed by lyophilization using a probe sonicator and a high-pressure homogenization method.[10] However, to our knowledge, there has been no report on the simultaneous determination of gallic acid and quercetin (Polyherbal nanoparticles) and amla and pomegranate peels (Polyherbal extract) in animal plasma after oral administration. In this study, a simple and sensitive HPLC-UV method was first developed and validated for simultaneous determination of gallic acid and quercetin nanoparticles as well as polyherbal extract in rat plasma. The method was demonstrated to be successful for application studies on pharmacokinetics of the two compounds after oral administration. 
In addition, we created a synergy strategy for the combination of active biomolecules and compared their activity to combined extracts in the treatment of colorectal cancer in rats. To our knowledge, no research has been published on the simultaneous detection of gallic acid and quercetin in animal plasma after oral administration of polyherbal nanoparticles and polyherbal extracts using high-performance liquid chromatography. After oral administration of polyherbal nanoparticles and polyherbal extracts, the approach was shown to be successful for applied research on the pharmacokinetics of the two biomolecules. Our findings support the use of hydrophilic mucoadhesive chitosan for the development of nanoparticles containing gallic acid and quercetin biomolecules that accumulate significantly in the colonic mucosa, tumor targeting, high efficacy in CRC rats, and improved bioavailability while achieving sustained release.

\section{Materials And Methods}

\subsection{Materials}

Poloxamer 407 was received from BASF, Chitosan 90 percent dda was got from CIFT Cochin, GMO was obtained from Mohini Organics, gallic acid and quercetin were obtained from Loba Chemie, and 1, 2Dimethylhydrazine (DMH) was obtained from TCl Chemicals in Chennai, India. HPLC-grade solvents was used for analysis and purchased from Himedia Laboratories, All other reagents were of analytical grade provided by Research Lab, Mumbai, provided all other solvents and chemicals.

\subsection{Estimation of pharmacokinetic parameters and statistical significance}

The plasma concentrations of the analytes were represented as mean SD at various time points, and mean concentration-time curves were produced. Individual plasma-concentration time data for Gallic acid and quercetin were used to determine the maximum plasma concentration (Cmax) and time to achieve Cmax (Tmax) after polyherbal nanoparticle administration. Using linear trapezoidal summing with

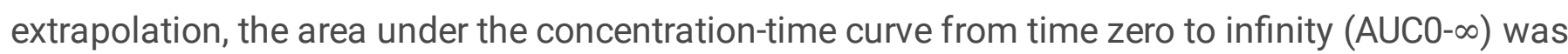
calculated. The terminal elimination rate constant (ke) was calculated using linear least square regression analysis of the plasma-concentration time curve's terminal log-linear component. The distribution's half-life ( $\mathrm{t} 1 / 2$ ) was also determined. The data were presented as a mean standard deviation. The unpaired student t-test was used to compare the data of two samples using the GraphPad prism program and $\mathrm{P}<0.0001$ was judged statistically significant. HPLC was used to evaluate the samples.[11]

\section{Formulation Of Polyherbal Nanoparticles}

Using a GMO/chitosan-TPP framework, an o/w nanoemulsion containing gallic acid and quercetin was synthesized with minor modifications. In a probe sonicator, isolated gallic acid (100 mg) and quercetin $(100 \mathrm{mg})$ were dissolved in molten GMO $(1.75 \mathrm{~g})$, and then $12.5 \mathrm{ml}$ of $0.1 \%$ poloxamer 407 was added 
and sonicated at $18 \mathrm{~W}$ for $3 \mathrm{~min}$. The method of ionic gelation was used to prepare nanoparticles. Lowmolecular-weight Chi was dissolved in $1 \% \mathrm{v} / \mathrm{v}$ acetic acid to produce a chitosan solution $(2.4 \% \mathrm{~W} / \mathrm{v})$. Polyherbal nanoparticles were formed spontaneously after adding various concentrations of TPP $(0.015 \%, 0.02 \%, 0.025 \%$, and $0.03 \% \mathrm{w} / \mathrm{v})$ to chitosan solution for 1 hour at room temperature with mild magnetic stirring. [12] The volume ratio of chitosan: TPP solution was 2:1 in all cases. $12.5 \mathrm{~mL}$ chitosanTPP solution was added dropwise to the initial emulsion in a probe sonicator for 30 minutes at room temperature under vigorous mechanical stirring. Finally, this phase was lyophilized with $1 \%$ mannitol as a cryoprotectant for 48 hours after being treated to twelve cycles of high-pressure homogenizer at 15,000 psi to produce the nanoemulsion. [13][14][15]

\section{In Vivo Animal Activity}

The current study's protocol was approved by BVCPK/CPCSEA/IAEC/17/19, and the experimental procedure followed CPCSEA guidelines. Wistar rats were randomly divided into five groups, each with six animals; animals were examined every week for body weight and hematological parameters throughout the 14-week experiment. The OECD 425 recommendations were followed when testing the acute oral toxicity of polyherbal nanoparticles. For ten weeks, all animals (except group I) received i.p injections of DMH $(20 \mathrm{mg} / \mathrm{kg})$ once a week. The rats in group I was given regular saline throughout the experiment. For four weeks, animals in group III got 5-Fluorouracil nanoparticles $(10 \mathrm{mg} / \mathrm{kg})$, group IV received polyherbal extract ( $400 \mathrm{mg} / \mathrm{kg}$ ), and group $\vee$ received colon targeting polyherbal nanoparticles $(100 \mathrm{mg} / \mathrm{kg})$. Animals from each group were sedated for a pharmacokinetic study after 4 weeks of therapy. $[16,17]$

\section{Pharmacokinetic Study}

In comparison to polyherbal extract, a single-dose oral bioavailability study of polyherbal nanoparticles was designed in male Wistar rats under fasting conditions. [18] Animals were given polyherbal nanoparticles and polyherbal extract in a single oral dose after a week of acclimatization (polyherbal nanoparticles $100 \mathrm{mg} / \mathrm{kg}$ individually and polyherbal extract $400 \mathrm{mg} / \mathrm{kg}$ ).

\subsection{Dosing and sampling schedule}

Six rats were given polyherbal nanoparticles $(100 \mathrm{mg} / \mathrm{kg}$ of gallic acid and quercetin) and polyherbal extract $400 \mathrm{mg} / \mathrm{kg}$, which were dissolved in newly made $0.5 \% \mathrm{CMC}-\mathrm{Na}$ solution. After oral administration of polyherbal nanoparticles and polyherbal extract in Eppendorf tubes, blood samples of around $0.5 \mathrm{~mL}$ were withdrawn through retro-orbital venous plexus puncture at $0,0.5,1,1.5,2,3,4,6,8,10,12$, and 24 hours post doses. To separate plasma, the plasma was centrifuged at $3200 \mathrm{~g}$ for 30 minutes. The serum was transferred to a new Eppendorf tube and kept at -200C in HPLC analysis.[19]

\subsection{Instrumentation and analytical conditions}

The chromatographic analysis was carried out utilizing a Systronics HPLC PU-2080 Plus with a UV-2075 intelligent detector. In the pharmacokinetic study, the C18 column (250 mm $\times 4.6 \mathrm{~mm}, 5 \mu \mathrm{m}$,) was used 
for the analysis. The column temperature was maintained at $40^{\circ} \mathrm{C}$. At a flow rate of $1 \mathrm{ml} / \mathrm{min}$ for 10 minutes at $368 \mathrm{~nm}$, the isocratic mobile phase comprised of ACN: $0.2 \%$ Acetic acid (60:40 v/v). The injection volume was $20 \mu \mathrm{l}$. The mobile phase was filtered through to $0.45 \mu \mathrm{m}$ Millipore filter and degassed before use.[20]

\subsection{Preparation of stock and working solutions}

A stock solution of $5 \mathrm{mg} / \mathrm{ml}$ was prepared by dissolving gallic acid and quercetin in methanol. Working solutions for the assay of plasma samples were made by diluting the stock solution with methanol to the required concentration. The working solutions were made by diluting the stock solution with methanol in steps of $500,100,50,10$, and $5 \mu \mathrm{g} / \mathrm{ml} .[21]$

\subsection{Preparation of calibration standards and quality control samples}

By diluting the working solutions with drug-free rat plasma to generate final concentrations of $0.1,0.25$, $0.5,1,5,7.5,10,15$, and $25 \mu \mathrm{g} / \mathrm{ml}$ gallic acid and quercetin, calibration standards were prepared in drugfree rat plasma at various concentrations. Gallic acid and quercetin stock solutions were produced by dissolving them in methanol to a final concentration of $0.11 \mathrm{mg} / \mathrm{ml}$. In methanol, a stock solution of polyherbal nanoparticles and polyherbal extracts was generated, which was then diluted further. All of the solutions were kept at $40^{\circ} \mathrm{C}$ and sheltered from light. Quality control samples were generated in the same way as the calibration samples and represented three distinct levels of gallic acid and quercetin in plasma (low, medium, and high) at 0.57, 2.84, and $9.09 \mu \mathrm{g} / \mathrm{ml}$, respectively[22]

\subsection{Optimization of sample preparation conditions}

Initially, we employed the protein precipitation method, which involved adding $1 \mathrm{~mL}$ acetonitrile to the mixture. However, the results showed that protein precipitation could not completely separate the desired chemicals from the proteins and interfering peaks in rat plasma. This procedure is quick, and the extraction is easy, with no analyte loss.[23]

\subsection{Pretreatment of plasma samples}

$100 \mu \mathrm{L}$ plasma samples were added to $200 \mu \mathrm{L}$ ACN/Acetic acid 100:5 (v/v) solutions. Each tube was thoroughly mixed for 3 minutes using a vortex mixer before being centrifuged for 10 minutes at $13839 \mathrm{~g}$. The liquid from the supernatant was collected for HPLC analysis. After rehydrating the extracted sample in the mobile phase, $20 \mathrm{~mL}$ of ultra-filtrate was injected onto the HPLC column.[24] Gallic acid and quercetin in nanoformulation had retention periods of 2.47 and 4.37 minutes, respectively, but gallic acid and quercetin in polyherbal extract had retention times of 2.45 and 4.33 minutes, as had shown in figure 1.

\section{Result And Discussion}

\subsection{Formulation of polyherbal nanoparticles}


The goals of this study are to optimize particle size minimization utilizing a central composite factorial design, as outlined in experimental component number one. The best conditions for making polyherbal nanoparticles were $2.4 \%$ chitosan-TPP and $0.1 \%$ poloxamer (407). [25]

\subsection{Characterization of polyherbal nanoparticles 6.2.1 Analysis of particle size and zeta potential}

With a zeta potential of $+25.7 \pm 0.15 \mathrm{mV}$, the mean diameter of polyherbal nanoparticles was found to be $147.8 \pm 2.216 \mathrm{~nm}$. Because chitosan has a positive charge due to the presence of protonated amino groups, here concluded that positively charged polyherbal nanoparticles that were appropriate to adhere negatively charge intestinal mucin hence to enhance oral bioavailability of the same.

\subsubsection{FTIR of polyherbal nanoparticles}

In the spectrum of gallic acid shown in figure $2 \mathrm{~A}$, there is a broad band at $3194.61 \mathrm{~cm}^{-1}$ related to $\mathrm{OH}$ stretching and hydrogen bonds between phenolic hydroxyl groups.

The $\mathrm{C}-0$ stretching length is $1021.45 \mathrm{~cm}^{-1}$. A broad band at $3194.61 \mathrm{~cm}^{-1}$ in the spectra of quercetin given in figure no $2 \mathrm{~B}$ is attributed to $\mathrm{OH}$ stretching and hydrogen bonding between phenolic hydroxyl groups also, $3190.38 \mathrm{~cm}^{-1}$ for $\mathrm{O}-\mathrm{H}$ stretch, and $1145.06 \mathrm{~cm}^{-1}$ for aromatic C-O stretch. The O-H stretch of gallic acid and quercetin was absent in the spectra of gallic acid and quercetin loaded polyherbal nanoparticles had shown in figure no $2 \mathrm{C}$. Here all data of FTIR results conclude that encapsulation of gallic acid and quercetin into polyherbal nanoparticles with intermolecular hydrogen bonding occurred in the nanoformulation.[26]

\subsubsection{X-ray diffraction studies}

The characteristic peaks of quercetin at $12.46^{\circ}$ had shown in figure no. $3 \mathrm{~A}$, gallic acid at $16.43^{\circ}$ had shown in figure no. 3B, poloxamer 407 at $19.2^{\circ}$ corresponding to the crystallographic planes and chitosan at $23.96^{\circ}$ in amorphous form had shown in figure no. 3C. XRD pattern of polyherbal nanoparticles peaks at above diffraction angle disappeared; that both biomolecules incorporated into the nanoparticles in an amorphous state.[27]

\subsection{Data analysis}

\subsubsection{Selectivity}

The selectivity of the method was tested by comparing the chromatograms of blank plasma, spiked plasma, and actual plasma samples after orally administered $100 \mathrm{mg} / \mathrm{kg}$ of gallic acid and quercetin. Analytes were well separated and no interferences were detected from endogenous substances.

\subsubsection{Linearity, limits of detection and quantification}


The linear regression of the investigated gallic acid and quercetin in rat plasma was constructed by plotting peak area with the concentration of standard solutions. The calibration curves showed good linearity over the concentration range $0.1544-8.256 \mu \mathrm{g} / \mathrm{ml}$ for gallic acid with a correlation coefficient $\left(R^{2}\right)$ larger than 0.996 , and $0.1634-7.568 \mu \mathrm{g} / \mathrm{ml}$ for quercetin with $R^{2}$ larger than 0.997 . The mean standard curves were typically described by the equations: $Y=7437.9 X+924.65$ for rutin and $Y=7876.6$ $X+157.62$ for quercetin. The limits of detection ( $L O D, S / N=3$ ) and the lower limit of quantification (LLOQ, $S / \mathrm{N}=9$ ) were $0.0451 \mu \mathrm{g} / \mathrm{ml}$ and $0.1630 \mu \mathrm{g} / \mathrm{ml}$ for rutin and $0.0402 \mu \mathrm{g} / \mathrm{ml}$ and $0.1534 \mu \mathrm{g} / \mathrm{ml}$ for quercetin.

\subsubsection{Accuracy and precision}

The method's precision was assessed by the determination of QC samples $(n=6)$ on three different validation days. Intra-day precision was determined by assaying standard solutions of the analyte at different times during the same day. Inter-day precision was determined by assaying standard solutions of the analyte over three consecutive days. Here all data summarized in table no 1 . The concentration of each sample was determined using a calibration curve prepared each day.

Table No. 1: Precision and accuracy of gallic acid and quercetin in rat plasma $(n=6)$

\begin{tabular}{|c|c|c|c|c|c|c|}
\hline \multirow{2}{*}{$\begin{array}{l}\text { Nominal } \\
\text { conc. } \\
(\mu \mathrm{g} / \mathrm{ml})\end{array}$} & \multicolumn{4}{|l|}{ Intra-day } & \multicolumn{2}{|l|}{ Inter-day } \\
\hline & $\begin{array}{l}\text { Measured } \\
\text { conc. } \\
(\mu \mathrm{g} / \mathrm{ml})\end{array}$ & $\begin{array}{l}\text { Accuracy } \\
\text { (\%) }\end{array}$ & $\begin{array}{l}\text { Precision } \\
\text { RSD (\%) }\end{array}$ & $\begin{array}{l}\text { Measured } \\
\text { conc. } \\
(\mu \mathrm{g} / \mathrm{ml})\end{array}$ & $\begin{array}{l}\text { Accuracy } \\
\text { (\%) }\end{array}$ & $\begin{array}{l}\text { Precision } \\
\text { RSD (\%) }\end{array}$ \\
\hline \multicolumn{7}{|c|}{ Gallic acid } \\
\hline 0.201 & $0.206 \pm 0.008$ & 99.6 & 3.42 & $0.187 \pm 0.128$ & 96.7 & 4.02 \\
\hline 1.553 & $1.745 \pm 0.127$ & 99.3 & 2.26 & $1.704 \pm 0.140$ & 98.3 & 2.56 \\
\hline 4.072 & $3.458 \pm 0.127$ & 98.5 & 2.12 & $3.20 \pm 0.671$ & 97.4 & 2.34 \\
\hline \multicolumn{7}{|l|}{ Quercetin } \\
\hline 0.184 & $0.193 \pm 0.144$ & 98.2 & 1.93 & $0.134 \pm 0.356$ & 98.4 & 3.31 \\
\hline 1.567 & $1.479 \pm 0.725$ & 95.4 & 1.65 & $1.561 \pm 0.129$ & 94.7 & 1.93 \\
\hline 3.860 & $3.838 \pm 0.106$ & 97.4 & 1.22 & $3.850 \pm 0.237$ & 91.2 & 1.72 \\
\hline
\end{tabular}

\subsubsection{Extraction recovery}

The mean extraction recoveries of quercetin from rat plasma at concentrations of $0.2014,1.553$, and $4.072 \mu \mathrm{g} / \mathrm{ml}$ were $99.6,99.3$, and $98.5 \%$ respectively. The mean extraction recoveries of quercetin from rat plasma at concentrations of $0.1340,1.561$, and $3.850 \mu \mathrm{g} / \mathrm{ml}$ were $98.4,94.7$, and $91.2 \%$ respectively. 


\subsubsection{Stability}

The stabilities of $0.2014,1.553$ and $4.072 \mu \mathrm{g} / \mathrm{ml}$ gallic acid, or $0.1340,1.561$ and $3.850 \mu \mathrm{g} / \mathrm{ml}$ quercetin in rat plasma were tested in room temperature for $12 \mathrm{~h}, 4^{\circ} \mathrm{C}$ for $24 \mathrm{~h}$ and $-20^{\circ} \mathrm{C}$ for one week. No significant degradation of gallic acid (1) or quercetin (2) was detected under any of these conditions.

\subsubsection{Pharmacokinetic analysis}

The purpose of the study is to determine whether the particle size of the gallic acid and quercetin in nanoparticle formulation can increase the bioavailability and as well as decrease the fluctuations of the drug concentration in the plasma and also dose associated adverse effects when compared with polyherbal extracts. The sensitivity and specificity of the proposed method were found to be sufficient for the accurate quantification of gallic acid and quercetin in nanoformulation in rat plasma after a single oral dietary dose of $100 \mathrm{mg} / \mathrm{kg}$ separately.

Therefore we utilized the method to study the pharmacokinetics of gallic acid and quercetin in rats. Following figure no. 4 shown the plasma concentration-time profile of nanoformulation and extract in rats and demonstrates that it is best described by a one-compartment model. Gallic acid and quercetin in nanoformulation were rapidly absorbed and achieved a peak level at $6 \mathrm{~h}$ and $5 \mathrm{~h}$ and in herbal extract, it was obtained at $3 \mathrm{~h}$ respectively. Thereafter, both the biomolecules in nanoformulation underwent a distribution phase with a half-life of $4.59 \mathrm{~h}$ and $3.59 \mathrm{~h}$., followed by an elimination phase with approximately 0.15 and $0.19 \mathrm{~h}$. Table no 3 shown that the pharmacokinetic parameters of gallic acid and quercetin in nanoformulation and herbal extract in rats following oral administration of a single dose of $100 \mathrm{mg} / \mathrm{kg}$.

These controversies in pharmacokinetic parameters could be attributed to different reasons, mainly the differences in study design. While in our study we used polyherbal extract and polyherbal nanoparticles containing gallic acid and quercetin, and as compared to extract targeted nanoparticles which exhibit greater stability at the $\mathrm{pH}$ and temperature of the colon, we have used both biomolecules in nanoformulation which is chemically stable under these conditions. In our study, we have compared polyherbal nanoparticle study with a polyherbal extract containing both the biomolecules, utilized $100 \mathrm{mg} / \mathrm{kg}$ of gallic acid and quercetin in nanoformulation which was lower than the polyherbal extract containing gallic acid and quercetin $400 \mathrm{mg} / \mathrm{kg}$ here all data summarized in table no 2.[29]

Table no. 2 Results of comparative bioavailability study of polyherbal extract and polyherbal nanoformulation 


\begin{tabular}{|c|c|c|c|c|}
\hline $\begin{array}{l}\text { Pharmacokinetic } \\
\text { Parameters }\end{array}$ & $\begin{array}{l}\text { Herbal Extract } \\
\text { (Gallic acid) }\end{array}$ & $\begin{array}{l}\text { Polyherbal } \\
\text { nanoformulation ( } \\
\text { Gallic acid) }\end{array}$ & $\begin{array}{l}\text { Herbal Extract } \\
\text { (Quercetin) }\end{array}$ & $\begin{array}{l}\text { Polyherbal } \\
\text { nanoformulation } \\
\text { (Quercetin) }\end{array}$ \\
\hline Cmax $(\mu \mathrm{g} / \mathrm{ml})$ & $0.7274 \pm 0.102^{\star \star \star}$ & $0.6957 \pm 1.52 * \star$ & $0.7080 \pm 0.219 * \star \star$ & $0.8551 \pm 0.353^{\star \star}$ \\
\hline $\operatorname{tmax}(\mathrm{h})$ & $3 \pm 0.0$ & $6 \pm 0.0$ & $3 \pm 0.0$ & $5 \pm 0.0$ \\
\hline AUC $\ln (h * \mu g / m l)$ & $3.8427 \pm 1.40 * *$ & $6.6086 \pm 1.51^{\star \star \star}$ & $3.4871 \pm 0.6^{\star *}$ & $5.6734 \pm 2.64^{\star \star \star \star}$ \\
\hline $\begin{array}{l}\text { AUCO- } \\
12\left(h^{\star} \mu \mathrm{g} / \mathrm{ml}\right)\end{array}$ & $3.8219 \pm 0.40 * \star$ & $5.0617 \pm 2.01 * \star$ & $3.3870 \pm 1.8^{\star \star \star \star}$ & $4.8073 \pm 0.44$ *夫 \\
\hline $\mathrm{t} 1 / 2(\mathrm{~h})$ & $1.07 \pm 17.51^{\star \star \star \star}$ & $4.59 \pm 1.36^{\star \star}$ & $2.078 \pm 1.27 \star \star$ & $3.5998 \pm 1.21$ ** \\
\hline $\mathrm{KE}(\mathrm{h})$ & $0.6449 * *$ & $0.15088^{\star \star}$ & $0.3334 * \star$ & $0.19251 * \star$ \\
\hline
\end{tabular}

\section{Discussion}

Therefore, the results confirmed that the polyherbal nanoparticles (Gallic acid isolated from amla and quercetin isolated from pomegranate fruit peel extract) showed significant improvement in oral bioavailability and anti-colon cancer activity than polyherbal extracts of amla and pomegranate fruit peel. The pharmacokinetic results would be a suitable reference in the clinical application of polyherbal nanoparticles. The improvement in the peak concentration might be due to the decreased particle size and also an indication of the absorption of the drug. Further, the obtained results revealed a higher plasma drug concentration and longer time taken to peak plasma concentration for polyherbal nanoformulation compared with polyherbal extract of amla and pomegranate fruit peel extract.[30]

Statistically significant improvement in the AUC total of the formulation was observed and was found to be $6.6086 \pm 1.51 \mathrm{ug} \mathrm{h} / \mathrm{mL}$ and $5.6734 \pm 2.64 \mathrm{ug} \mathrm{h} / \mathrm{mL}$ for polyherbal nanoparticles of gallic acid and quercetin respectively which was isolated, from amla and pomegranate fruit peel extracts. This is indicative of the enhancement in the oral bioavailability of both the biomolecules in nanoformulation when compared to present in polyherbal extracts. The half-life of the nanoformulation was near two folds more than the polyherbal extracts, this shown the improved residence time and also a prolonged release of drug from the nanoformulation to the targeted colonic site. The improvement in the bioavailability of both the biomolecules from polymeric nanoparticles can be related to the surface area for absorption is increased due to the small droplet size of the biomolecules. It is also obvious that the nanoparticle formulations are absorbed by the colonic site, avoiding absorption in the GIT, which is one of the finest important reasons for enhanced bioavailability.[31]

\section{Conclusion}

In comparison to modern pharmaceuticals, plant-based medicines have been widely used by physicians and patients all over the world for their superior therapeutic value and fewer adverse effects. The 
bioavailability of nano-preparation was enhanced over polyherbal extract of amla and pomegranate fruit peel due to reduced absorption and excretion rates. Herbal medications' medicinal effectiveness can be boosted by employing various scientific methodologies to make them more target specific, hence reducing potential negative effects. The capacity of herbal medications used in colonic disorders to reach the site of action determines their therapeutic potential.

\section{Ethical Statement}

\section{- Ethics approval and consent to participate}

For this study, prior clearance from an institutional animal ethics committee (approval number BVCPK/CPCSEA/IAEC/17/19) was obtained and the experimental procedure followed CPCSEA guidelines.

\section{- Consent for publication}

The authors have read the final version and give their consents for the article to be published in Drug Delivery and Translational Research.

\section{- Availability of data and materials}

Data included in article / supplementary material / referenced in article.

\section{- Competing interests}

The authors declare that they have no conflict of interest.

- Funding

No any funding was received for this study.

\section{- Author contributions}

Ms. P. S. Patil: Conceived and designed the experiments; Contributed reagents, materials, analysis tools or data; Performed the experiments; Analyzed and wrote the paper.

Dr. S. G. Killedar: Conceived and designed the experiments; Analyzed and interpreted the data; wrote the paper.

\section{- Acknowledgement(s)}

The author(s) express their deep sense of gratitude towards Bharati Vidyapeeth College of Pharmacy, (Kolhapur, Maharashtra) and Government College of Pharmacy (Karad, Maharashtra) for provision of obligatory facilities to carry out present research work. Author(s) are profusely thankful to Dr. Riyaz Ali M. 
Osmani, Department of Biosciences and Bioengineering, Indian Institute of Technology Bombay, Mumbai, for his valuable inputs and constructive suggestions.

\section{References}

1. Gumireddy, A., et al., Preparation, characterization, and in vitro evaluation of curcumin-and resveratrol-loaded solid lipid nanoparticles. Aaps Pharmscitech, 2019. 20(4): p. 1-14.

2. Schirrmacher, V., From chemotherapy to biological therapy: A review of novel concepts to reduce the side effects of systemic cancer treatment. International journal of oncology, 2019. 54(2): p. $407-419$.

3. Martinez-Guryn, K., et al., Small intestine microbiota regulate host digestive and absorptive adaptive responses to dietary lipids. Cell host \& microbe, 2018. 23(4): p. 458-469. e5.

4. Steed, K., et al., The use of pharmacoscintigraphy to focus the development strategy for a novel 5-ASA colon targeting system ("TIME CLOCK®" system). Journal of controlled release, 1997. 49(2-3): p. 115-122.

5. Hanauer, S.B. and M. Sparrow, COLAL-PRED Alizyme. Current opinion in investigational drugs (London, England: 2000), 2004. 5(11): p. 1192-1197.

6. Dhir, K., H. Kahlon, and S. Kaur, Recent approaches for colon targeted drug delivery system. Research Journal of Pharmaceutical, Biological and Chemical Sciences, 2013. 4: p. 452-467.

7. Singh, N. and R. Khanna, Colon targeted drug delivery systems-A Potential Approach. The Pharma Innovation, 2012. 1(2).

8. Jain, A., Y. Gupta, and S.K. Jain, Perspectives of biodegradable natural polysaccharides for sitespecific drug delivery to the colon. J Pharm Pharm Sci, 2007. 10(1): p. 86-128.

9. Udompornmongkol, P. and B.-H. Chiang, Curcumin-loaded polymeric nanoparticles for enhanced anti-colorectal cancer applications. Journal of biomaterials applications, 2015. 30(5): p. 537-546.

10. Rahmani, F., E. Karimi, and E. Oskoueian, Synthesis and characterisation of chitosanencapsulated genistein: its anti-proliferative and anti-angiogenic activities. Journal of microencapsulation, 2020. 37(4): p. 305-313.

11. Yousuf, M.J. and E. Vellaichamy, Protective activity of gallic acid against glyoxal-induced renal fibrosis in experimental rats. Toxicology reports, 2015. 2: p. 1246-1254.

12. Mistry, P.H., S.K. Mohapatra, and A.K. Dash, Effect of high-pressure homogenization and stabilizers on the physicochemical properties of curcumin-loaded glycerol monooleate/chitosan nanostructures. Nanomedicine, 2012. 7(12): p. 1863-1876. 
13. Konecsni, K., N. Low, and M. Nickerson, Chitosan-tripolyphosphate submicron particles as the carrier of entrapped rutin. Food Chemistry, 2012. 134(4): p. 1775-1779.

14. Ramaswamy, S., et al., Formulation and characterization of chitosan encapsulated phytoconstituents of curcumin and rutin nanoparticles. International journal of biological macromolecules, 2017. 104: p. 1807-1812.

15. Basha, M., et al., Benzocaine loaded solid lipid nanoparticles: formulation design, in vitro and in vivo evaluation of local anesthetic effect. Current drug delivery, 2015. 12(6): p. 680-692.

16. Hamiza, 0.0., et al., Amelioration of 1, 2 Dimethylhydrazine (DMH) induced colon oxidative stress, inflammation and tumor promotion response by tannic acid in Wistar rats. Asian Pacific Journal of Cancer Prevention, 2012. 13(9): p. 4393-4402.

17. Rehman, M.U., et al., Chemopreventive effect of Quercus infectoria against chemically induced renal toxicity and carcinogenesis. Int J Drug Dev Res, 2012. 4(2): p. 336-351.

18. Dudhipala, N. and G. Puchchakayala, Capecitabine lipid nanoparticles for anti-colon cancer activity in 1, 2-dimethylhydrazine-induced colon cancer: preparation, cytotoxic, pharmacokinetic, and pathological evaluation. Drug development and industrial pharmacy, 2018. 44(10): p. 1572-1582.

19. Oyagbemi, A.A., et al., Gallic acid ameliorates cyclophosphamide-induced neurotoxicity in wistar rats through free radical scavenging activity and improvement in antioxidant defense system. Journal of dietary supplements, 2016. 13(4): p. 402-419.

20. Abdelkawy, K.S., M.E. Balyshev, and F. Elbarbry, A new validated HPLC method for the determination of quercetin: Application to study pharmacokinetics in rats. Biomedical Chromatography, 2017. 31(3): p. e3819.

21. Wang, T., et al., Green synthesized iron nanoparticles by green tea and eucalyptus leaves extracts used for removal of nitrate in aqueous solution. Journal of cleaner production, 2014. 83: p. 413-419.

22. Chaurasia, S., et al., Curcumin-polymeric nanoparticles against colon-26 tumor-bearing mice: cytotoxicity, pharmacokinetic and anticancer efficacy studies. Drug development and industrial pharmacy, 2016. 42(5): p. 694-700.

23. Abdifetah, $\mathrm{O}$. and $\mathrm{K}$. Na-Bangchang, Pharmacokinetic studies of nanoparticles as a delivery system for conventional drugs and herb-derived compounds for cancer therapy: a systematic review. International journal of nanomedicine, 2019. 14: p. 5659.

24. Huang, Q., et al., Glioma stem cells are more aggressive in recurrent tumors with malignant progression than in the primary tumor, and both can be maintained long-term in vitro. BMC cancer, 2008. 8(1): p. 1-11. 
25. Agarwal, U.P., et al., Production of high lignin-containing and lignin-free cellulose nanocrystals from wood. Cellulose, 2018. 25(10): p. 5791-5805.

26. Kavaz, E., An experimental study on gamma ray shielding features of lithium borate glasses doped with dolomite, hematite and goethite minerals. Radiation Physics and Chemistry, 2019. 160: p. 112-123.

27. Rampino, A., et al., Chitosan-pectin hybrid nanoparticles prepared by coating and blending techniques. European Journal of Pharmaceutical Sciences, 2016. 84: p. 37-45.

28. Trickler, W., A. Nagvekar, and A. Dash, A novel nanoparticle formulation for sustained paclitaxel delivery. Aaps Pharmscitech, 2008. 9(2): p. 486-493.

29. Xu, C., et al., A C8-modified graphene@ mSiO2 composites based method for quantification of gallic acid in rat plasma after oral administration of changtai granule and its application to pharmacokinetics. Biological and Pharmaceutical Bulletin, 2017. 40(7): p. 1021-1028.

30. Hosseinzadeh, $\mathrm{H}$., et al., Chitosan-Pluronic nanoparticles as oral delivery of anticancer gemcitabine: preparation and in vitro study. International journal of nanomedicine, 2012. 7: p. 1851.

31. Sumithra, S., R. Vadivu, and R. Radha, Colon Targeted Drug Delivery System of Phytoconstituents. Research Journal of Pharmacy and Technology, 2019. 12(7): p. 3144-3150.

\section{Figures}




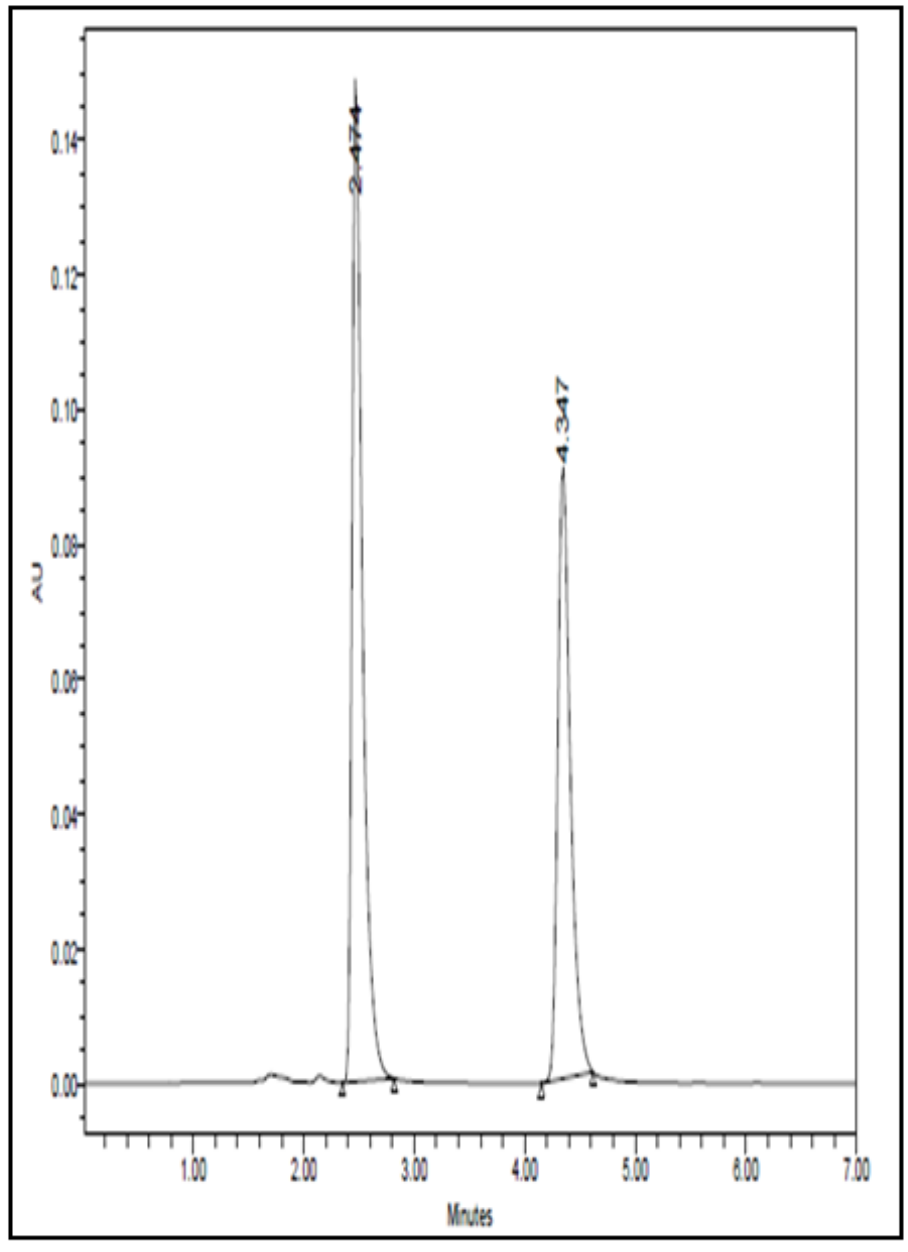

A

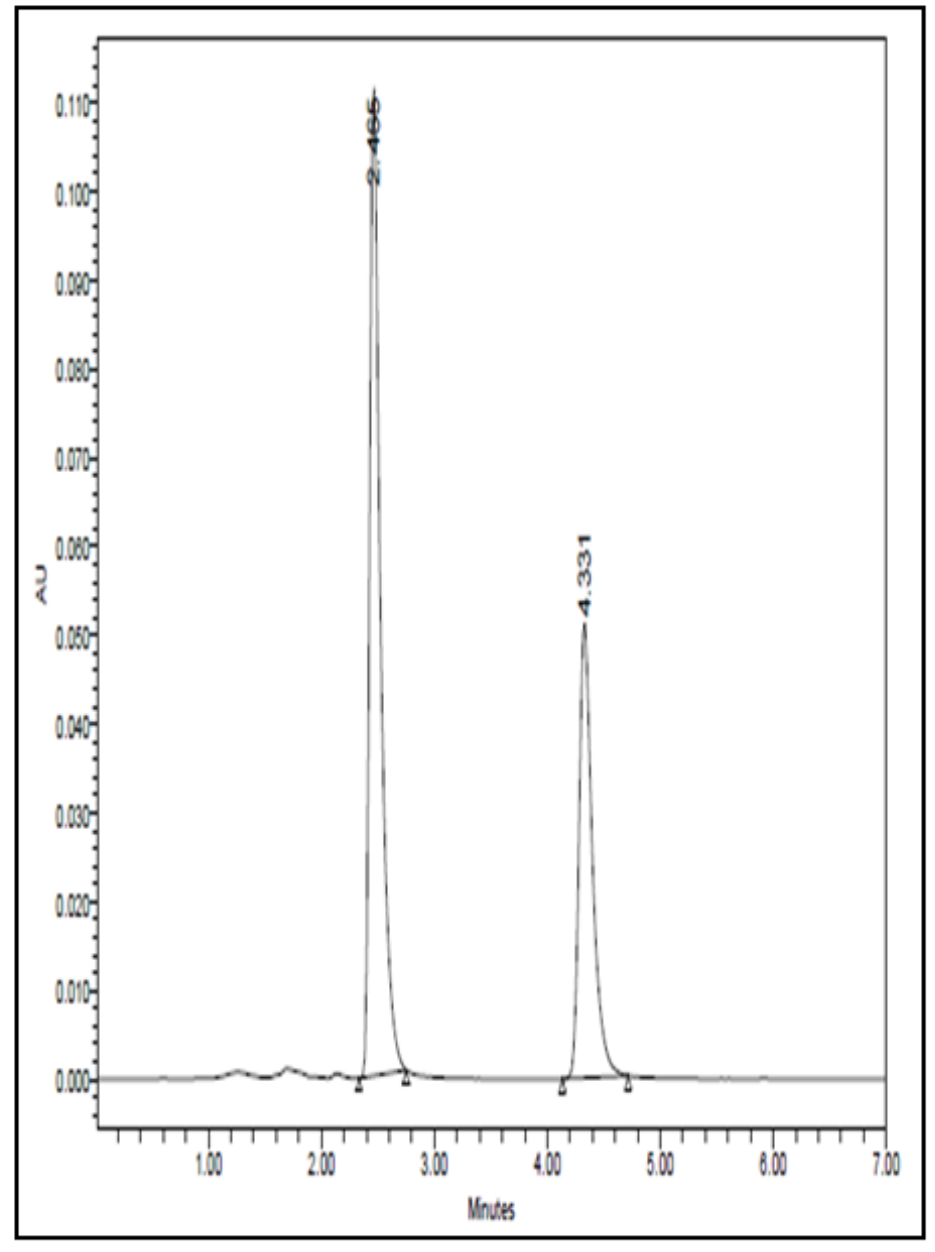

B

Figure 1

HPLC profiles of polymeric nanoparticles in rat plasma 


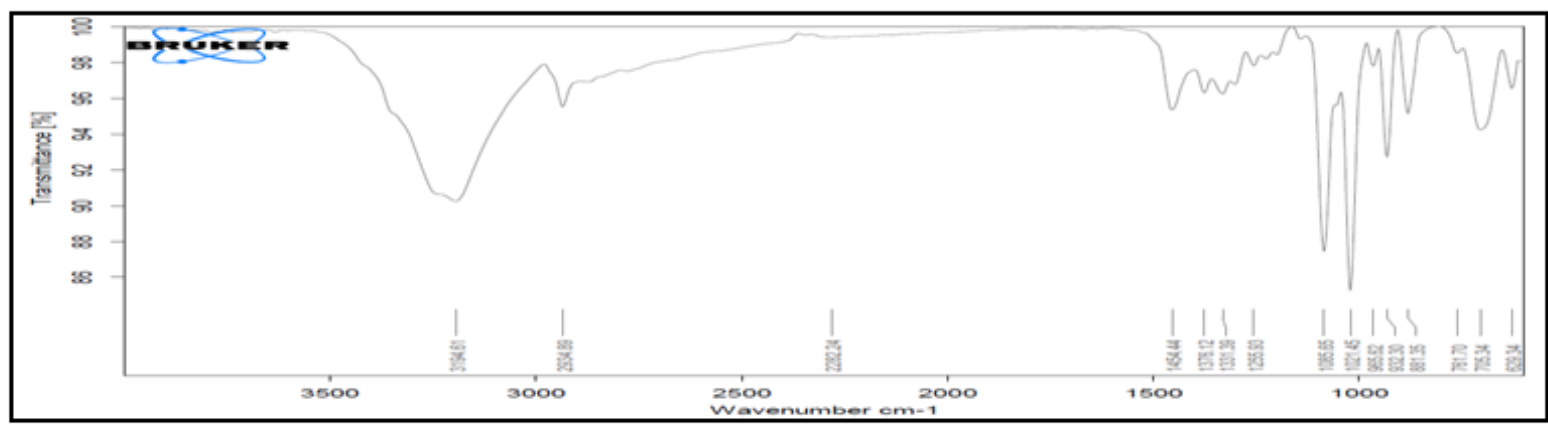

A

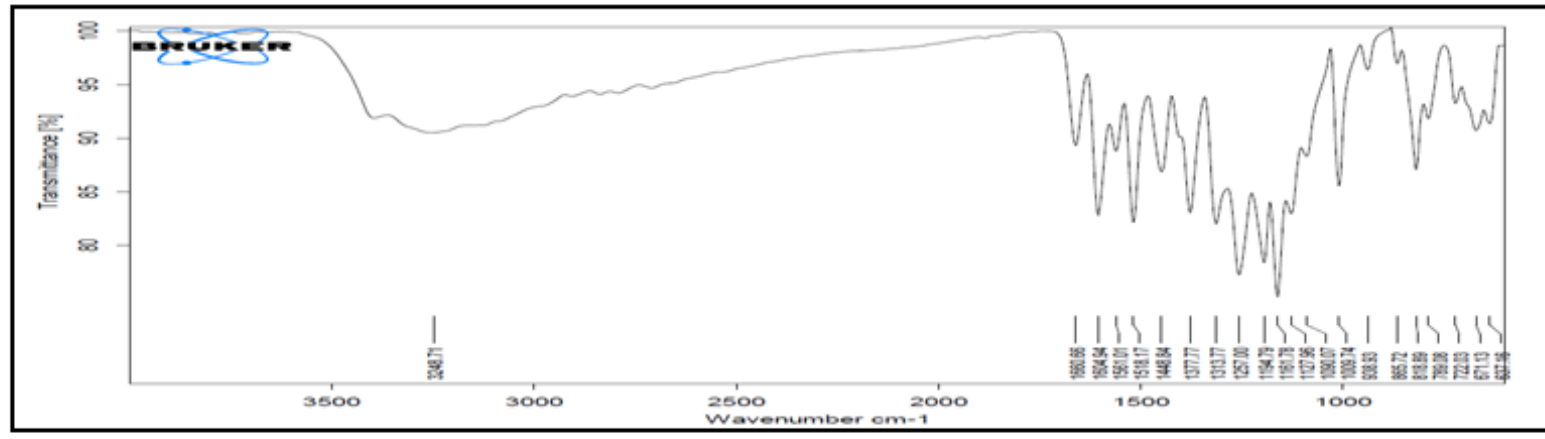

B

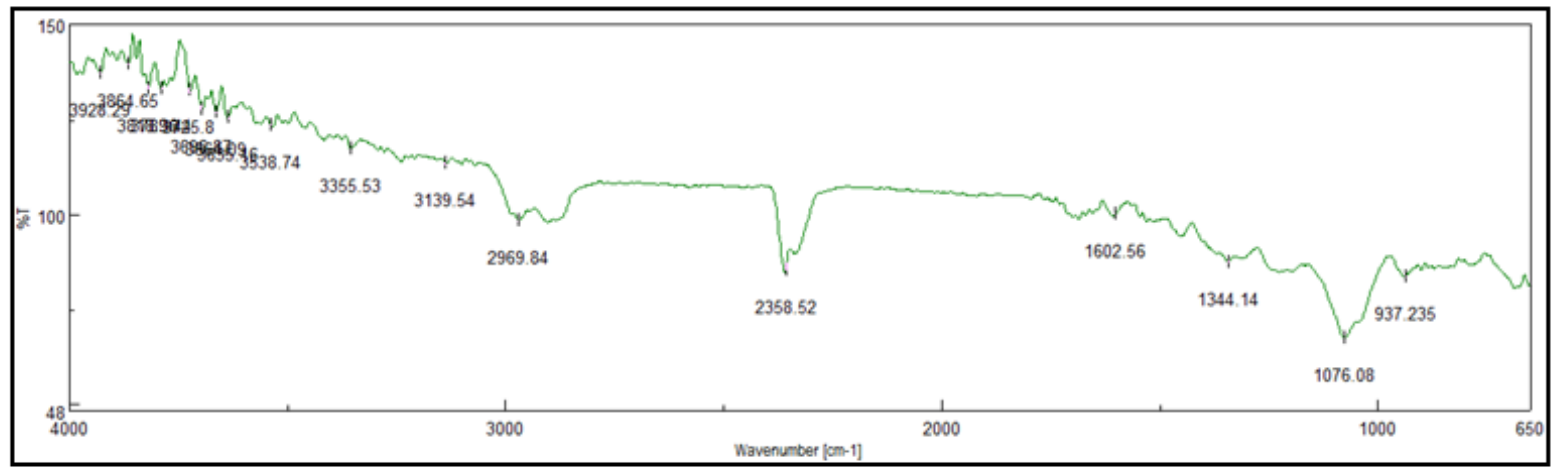

C

Figure 2

IR Spectra of (A) Gallic acid (B) Quercetin (C) Polyherbal nanoparticles

Figure 3

XRD Patterns of (A) Quercetin (B) Gallic acid (C) Polyherbal nanoparticles 


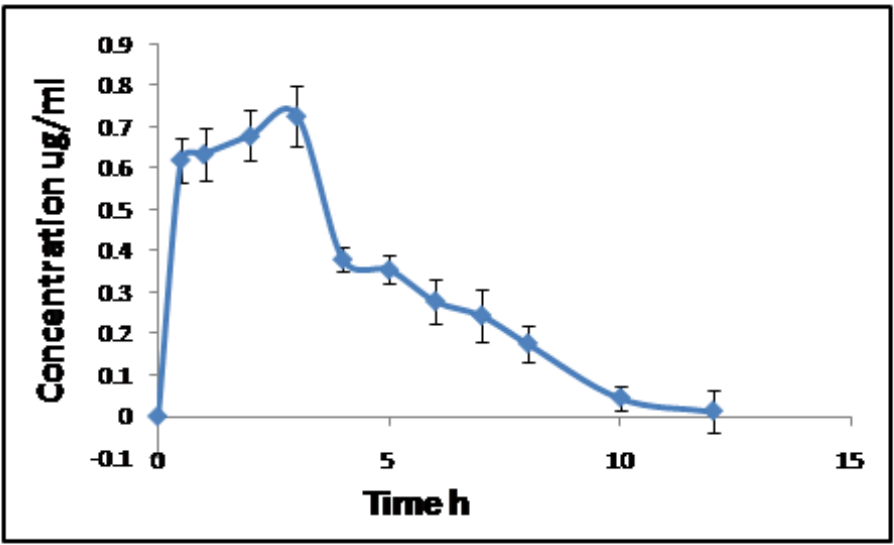

A

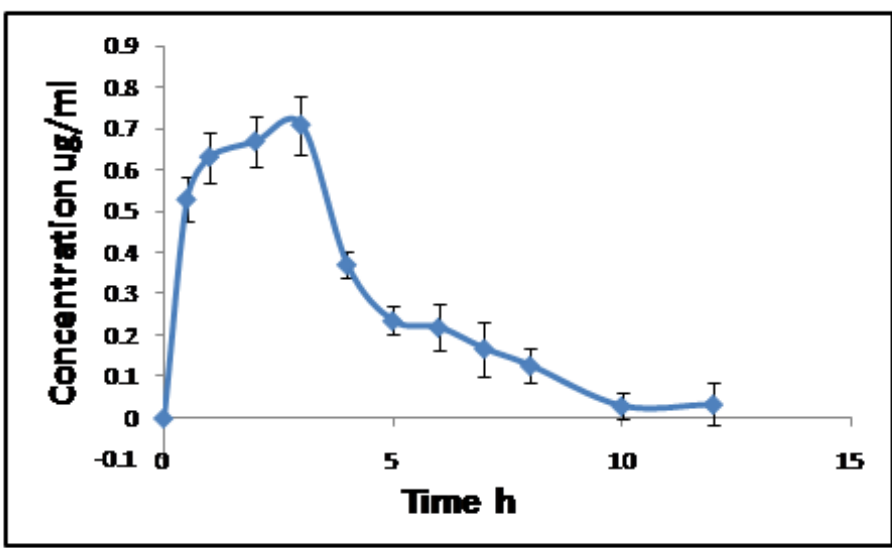

C

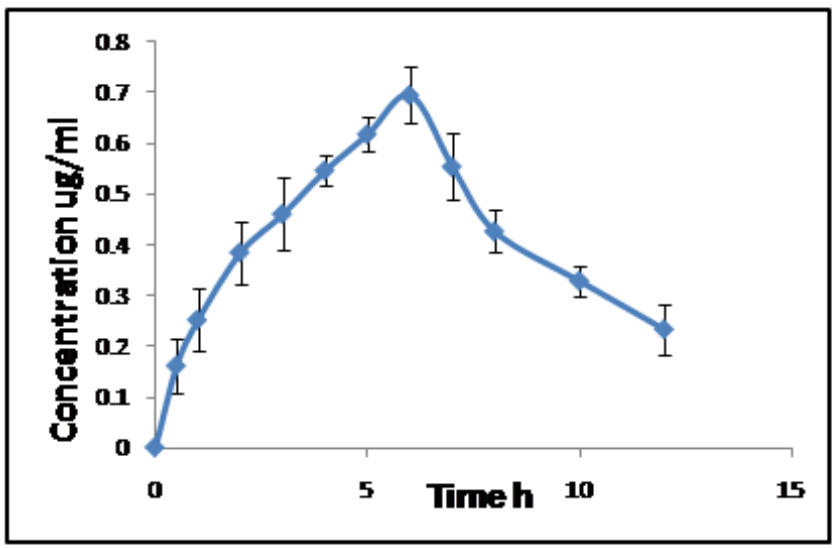

B

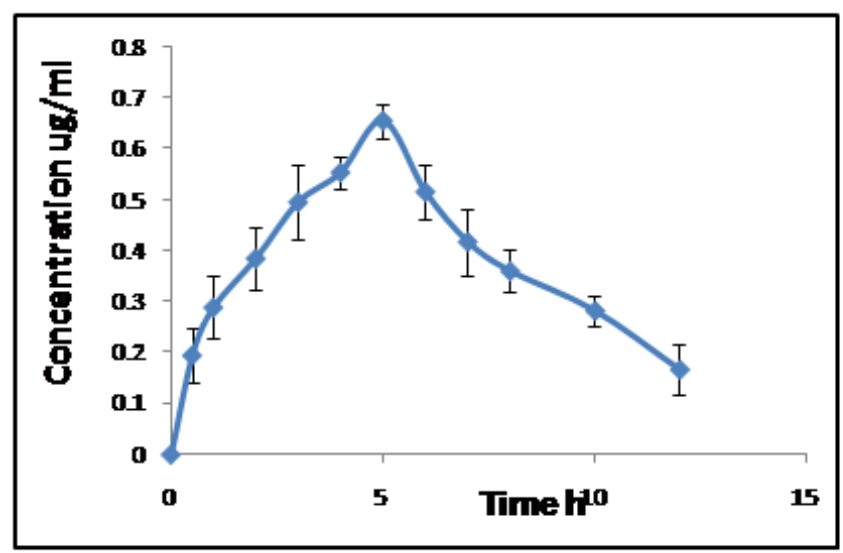

D

Figure 4

Plasma concentration time-profiles of (A) Gallic acid in herbal extract (B) Gallic acid in nanoformulation (C) Quercetin in herbal extract (B) Quercetin in nanoformulation 